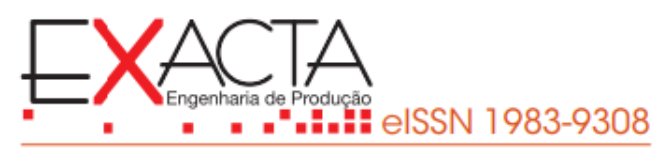

https://doi.org/10.5585/exactaep.v19n1.8940

Check for updates

\title{
ESTUDO DO PROCESSO DE TANQUES ISOTÉRMICOS RODOVIÁRIOS CILÍNDRICOS VISANDO AÇÕES DE MELHORIAS ATRAVÉS DO LEAN MANUFACTURING E MAPA DO FLUXO DE VALOR
}

\author{
STUDY OF THE PROCESS OF CYLINDRICAL ROAD ISOTHERMAL TANKS AIMED AT IMPROVEMENT \\ ACTIONS THROUGH LEAN MANUFACTURING AND VALUE FLOW MAP
}

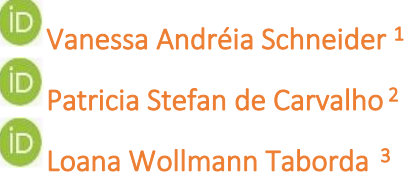

\begin{abstract}
${ }^{1}$ Mestra em Engenharia de Produção Universidade Federal de Santa Maria - UFSM vanessaandreias@gmail.com
\end{abstract}

\begin{abstract}
${ }^{2}$ Mestra em Engenharia de Produção Universidade Federal de Santa Maria - UFSM patrícia_stefanc@hotmail.com
\end{abstract}

${ }^{3}$ Mestra em Engenharia de Produção Faculdade Três de Maio - Setrem loanataborda@yahoo.com.br

Recebido em: 26 jul. 2018

Aprovado em: 06 nov. 2019

Cite como - American Psychological Association (APA)

Schneider, V. A., Carvalho, P. S de., \& Taborda, L. W. (2021, jan./mar.). Estudo do processo de tanques isotérmicos rodoviários cilíndricos visando ações de melhorias através do Lean Manufacturing e mapa do fluxo de valor. Exacta, 19(1), 35-51. https://doi.org/10.5585/exactaep.v19n1.8940.
Resumo: Devido à necessidade das empresas manterem-se competitivas, estudos de melhorias devem ser realizados constantemente nas indústrias, tendo a finalidade de minimizar despesas, desperdícios e maximizar lucros. O trabalho teve como objetivo analisar e estudar de maneira detalhada o processo de produção de tanques isotérmicos rodoviários, através do mapeamento de processos e mapa de fluxo de valor, visando propor ações de melhorias, seguindo os preceitos do lean manufacturing. Neste estudo de caso, através da pesquisa descritiva realizou-se a observação, análise e interpretação dos processos da linha de produção. Quanto às técnicas, foi utilizada a pesquisa documental e observação. Foi realizado o mapeamento de processos do produto em questão, estudando detalhadamente as peculiaridades da linha de produção. Posteriormente, desenvolveu-se o mapa do fluxo de valor presente, observando o fluxo de materiais e informações da cadeia produtiva. Um mapa do fluxo de valor futuro foi proposto, contribuindo com a empresa laboratório do estudo.

Palavras-chave: Processo de Produção. Mapeamento do Processo. Mapeamento do Fluxo de Valor. Lean Manufacturing.

Abstract: Due to the need for companies to remain competitive, improvement studies must be carried out constantly in the industries, with the purpose of minimizing expenses, waste and maximizing profits. The objective of this work was to analyze and study in detail the process of production of isothermal road tanks, through the mapping of processes and value flow map, aiming to propose improvements actions, following the precepts of lean manufacturing. In this case study, through the descriptive research was realized the observation, analysis and interpretation of the processes of the production line. As for the techniques, documentary research and observation was used. The process mapping of the product in question was carried out, studying in detail the peculiarities of the production line. Subsequently, the map of the flow of present value was developed, observing the flow of materials and information of the productive chain. A flow map of future value was proposed, contributing to the company's study laboratory.

Keywords: Production Process. Process Mapping. Mapping the Value Stream. Lean Manufacturing. 
Introdução

A qualidade do produto que chega ao consumidor final é o espelho do que ocorre em sua cadeia produtiva e em todos os processos, do projeto à venda. Assim, é evidente que a criação de mecanismos capazes de elevar a eficiência produtiva são importantes, e dessa forma, contribuindo no aumento do faturamento, além de incentivar na estrutura funcional da empresa (Santos, Hammes, Luz, Godoy, \& Ardenghi, 2016).

Uma metodologia essencial para o ambiente empresarial moderno, é a manufatura enxuta ou Lean Manufacturing, importante para que a organização adquira e retenha vantagem competitiva (Alhuraish, Robledo, \& Kobi, 2017). O Lean Manufacturing ou manufatura enxuta, concomitante ao mapa de fluxo de valor, têm sido amplamente utilizados para desenvolver processos de fabricação sem desperdícios no fluxo de produção (Helleno, Moraes, \& Simon, 2017).

Assim, uma empresa normalmente identifica quais de seus processos precisam ser melhorados e qual metodologia é compatível com essa necessidade (Alhuraish, Robledo, \& Kobi, 2017). Por esse motivo, entende-se que o desempenho do processo é fator fundamental e as melhorias devem ser continuamente buscadas, pois pequenas mudanças impactam na qualidade do produto, estabelecendo também melhores resultados organizacionais e financeiros.

Nesse viés, é crescente no mercado a procura por produtos e serviços personalizados, cujo foco é suprir as necessidades individuais de cada consumidor. Tanques isotérmicos podem ser customizados de acordo com especificações do cliente, sempre respeitando as normas e a engenharia do produto, o que torna um processo de alta diversidade. Este fator acaba dificultando a realização de processos padronizados. Em contrapartida, a qualidade do produto aliada com a customização do tanque de acordo com as necessidades do cliente, faz com que este fique satisfeito, criando um vínculo com a empresa para futuros negócios.

Nesse contexto, o que motivou o presente estudo foi a seguinte problemática: Como identificar e propor melhorias no processo produtivo de tanques isotérmicos rodoviários, a fim de contribuir com a empresa e na qualidade do produto final? Pois pelo fato de a empresa concedente do estudo apresentar alta produção e grande diversidade de produtos, indicava carência de procedimentos definidos e padronizados, apontando dificuldades de planejamento.

Cada vez mais as empresas buscam pela qualidade dos seus produtos e por processos bem alinhados, que gerem uma produção eficiente com custos bem ajustados. Com base nesse princípio, de modo a solucionar o problema em questão, o objetivo do estudo foi analisar e estudar de maneira detalhada o processo de produção de tanques isotérmicos rodoviários de 15000 I, através do mapeamento de processos e mapa de fluxo de valor, visando propor ações de melhorias e redução dos problemas existentes, seguindo os preceitos do lean manufacturing. 


\section{Referencial Teórico}

Manufatura enxuta e melhorias

A manufatura enxuta (Lean Manufacturing) tem como objetivo principal reduzir o desperdício dentro de uma organização (Alhuraish, Robledo, \& Kobi, 2017). Assim, a expressão "Lean" consiste em menor utilização em termos de insumos, tendo como conceito principal eliminar o desperdício (Chahal \& Narwal, 2017).

As melhorias realizadas devem evidenciar resultados, tanto na parte operacional, da qualidade do produto, como no que se refere às finanças. O sistema de manufatura enxuta consiste em um sistema de melhoria voltado para pessoas, podendo aperfeiçoar qualquer processo de trabalho, o que implica que seus princípios, ferramentas e práticas, podem melhorar qualquer tipo de trabalho em uma empresa (Koenigsaecker, 2011).

O Lean Manufacturing é amplamente utilizado nas organizações e indica a eliminação de resíduos, melhorando a qualidade e a produtividade dos processos realizados nas organizações de manufatura, focando na redução de custos, identificando e eliminando atividades que não agregam valor, eliminando o desperdício no processo de manufatura (Nallusamy, 2016). Para manter-se competitivo no mercado, as organizações precisam buscar constantemente melhorias, seja inovando ou melhorando seus processos para garantir que seus produtos sejam fabricados da melhor maneira, garantindo a qualidade ao consumidor, de forma ágil e organizada, e com o menor custo de produção.

Nesse contexto, no trabalho de Zahraee (2016), foram identificadas práticas e ferramentas eficazes de implementação de manufatura enxuta em uma indústria de fabricação iraniana. Os resultados deste trabalho, indicaram que processos e equipamentos, planejamento e controle, relacionamento com fornecedores, recursos humanos e relacionamento com clientes são práticas significativas em manufatura enxuta. Tortorella, Vergara e Ferreira (2017) buscaram compreender as lacunas existentes e as práticas críticas do Lean Manufacturing juntamente com a ergonomia dos trabalhadores em uma empresa brasileira fabricante de autopeças, abordando oportunidades de melhoria.

Na pesquisa de Condé e Martens (2018), o objetivo foi identificar um rol dos principais projetos Lean Manufacturing de acordo com a literatura científica, onde 11 projetos Lean foram identificados, servindo de referência para trabalhos futuros.

Assim, o sistema enxuto é uma filosofia de fluxo de valor que valoriza o cliente e elimina as perdas desse fluxo (Leite, Cotrim, Leal, \& Galdamez, 2017).

\section{Mapa de fluxo de valor}

Para Rother e Shook (2012), o mapeamento de fluxo de valor é uma ferramenta essencial que além de visualizar os processos individuais, permite ver o fluxo, ajudando a identificar as fontes de 
desperdício no fluxo de valor, fornecendo uma linguagem comum para tratar dos processos. Mapear o fluxo de valor consiste em observar diretamente o fluxo das informações e dos materiais/serviços no estado atual, focando no resultado futuro (Womack \& Jones, 2011).

O mapa de fluxo de valor é empregado como ferramenta principal para identificar as oportunidades de técnicas de melhorias (Nallusamy, 2016). O resultado do mapa de fluxo de valor é um mapa de uma única página que documenta graficamente os processos no estado atual e, depois de analisado, são identificadas suas fontes de resíduos, e o processo de construção do mapa de estado futuro é iniciado (Atieh, Kaylani, Almuhtady, \& Tamini, 2016).

Diversos estudos tendo como viés o mapa do fluxo de valor são elaborados. O estudo realizado por Prates e Bandeira (2011), consistiu no aumento da eficiência produtiva por meio do mapeamento de fluxo de valor. Bartz, Weise e Ruppenthal (2013), elaboraram o mapeamento de processos, com o fim de identificar as atividades que não agregavam valor ao produto, apresentando ações de melhoria.

Helleno, Moraes e Simon (2017), desenvolveram um método que integra um novo grupo de indicadores de sustentabilidade no mapa de fluxo de valor, para avaliar processos de fabricação. No trabalho de Leite et al. (2017), o objetivo foi apresentar uma proposta de melhoria de processo através da ferramenta mapa de fluxo de valor em uma empresa de manufatura.

Oliveira, Corrêa e Nunes (2013) empregaram a ferramenta de mapeamento do fluxo de valor, apresentando o mapa atual e os mapas futuros, a fim de apontar os desperdícios na produção e assim, quantificando possíveis melhorias ou modificações, com a finalidade de auxiliar na tomada de decisão.

\section{Metodologia}

\section{Objeto de estudo}

Quanto aos métodos de abordagem, foram utilizadas a qualitativa e quantitativa. A primeira foi aplicada na qualidade do produto fabricado e na identificação de possíveis melhorias. A pesquisa quantitativa está presente na quantificação de resultados obtidos e traduzidos em números, apresentados através de planilhas eletrônicas.

Quanto aos procedimentos, fez-se o uso da pesquisa descritiva, e estudo de caso. A pesquisa descritiva deu-se a partir da observação de fatos e particularidades, posterior registro, análise e interpretação dos processos da linha de produção. Usou-se o estudo de caso na análise da realidade da empresa, cuja finalidade foi analisar um fluxo produtivo em especial, analisando seus processos, visando melhorias e qualidade ao apresentar os resultados do trabalho em questão.

A empresa laboratório do estudo, destaca-se na fabricação de tanques isotérmicos rodoviários, distribuindo seu produto para todo o território nacional, devido à alta qualidade e comprometimento com o cliente. A mesma cresceu significativamente ano após ano, tornando-se referência no mercado de fabricação de tanques rodoviários isotérmicos, tanques resfriadores, tanques estacionários e diversos produtos fabricados em inox, inclusive projetos especiais. 
Em virtude do número de produtos que podem ser fabricados, bem como a possibilidade de customização dos mesmos, a realização de processos de forma padronizada é dificultada. Mesmo que o produto final seja entregue ao cliente de acordo com suas solicitações, muitas coisas acontecem durante o processo de produção, que podem ser mascaradas quando não ocorre a devida atenção do ciclo produtivo. Um exemplo disso é o desperdício de tempo e matéria-prima, que não são percebidos em virtude da carência de procedimentos para auxiliar no controle da produção.

Os tanques rodoviários isotérmicos são diferenciados uns dos outros pela capacidade de carregamento, quantidade de eixos e formato. Definiu-se mapear o processo produtivo de tanques isotérmicos de 15000 I, em virtude de sua frequência de fabricação e importante papel para a empresa.

\section{Procedimentos de coleta de dados}

Um registro do detalhamento da linha de produção de tanques isotérmicos rodoviários cilíndricos de 15000 I foi realizado. Além de entrevistas informais com os profissionais da indústria, com os responsáveis pela área administrativa e fabril, bem como com os colaboradores da empresa na busca de melhores informações sobre o processo produtivo e suas particularidades.

A técnica de observação foi utilizada no momento das observações dos processos produtivos para posterior mapeamento e sugestão de melhorias. A pesquisa documental foi utilizada através de buscas por informações em registros já existentes na indústria, como cartão de produção e dados de produção.

\section{Procedimentos de análise de dados}

Uma planilha eletrônica foi alimentada com dados, realizando um comparativo e análise. A ferramenta Microsoft Office Excel foi utilizada também na construção de uma tabela que auxilia o entendimento do processo. Utilizou-se a ferramenta Microsoft Visio para desenvolver o mapeamento do fluxo de valor.

No referido estudo, foi mapeada a linha de tanques isotérmicos rodoviários cilíndricos de 15000 I (Figura 1), com o objetivo de identificar oportunidades de melhorias, realizar análises e sugerir mudanças.

Primeiramente foram explorados os setores para melhor compreensão dos equipamentos utilizados e de como a produção ocorre. A transformação da matéria-prima percorre setores compostos de pessoas, máquinas e equipamentos que agregam gradativamente valor ao material inicial. A lógica do processo produtivo é a mesma para todos os modelos de tanques, no entanto alguns têm detalhes específicos adicionados de acordo com o pedido realizado, o que personaliza parcialmente a produção. 
Figura 1 - Exemplo do item

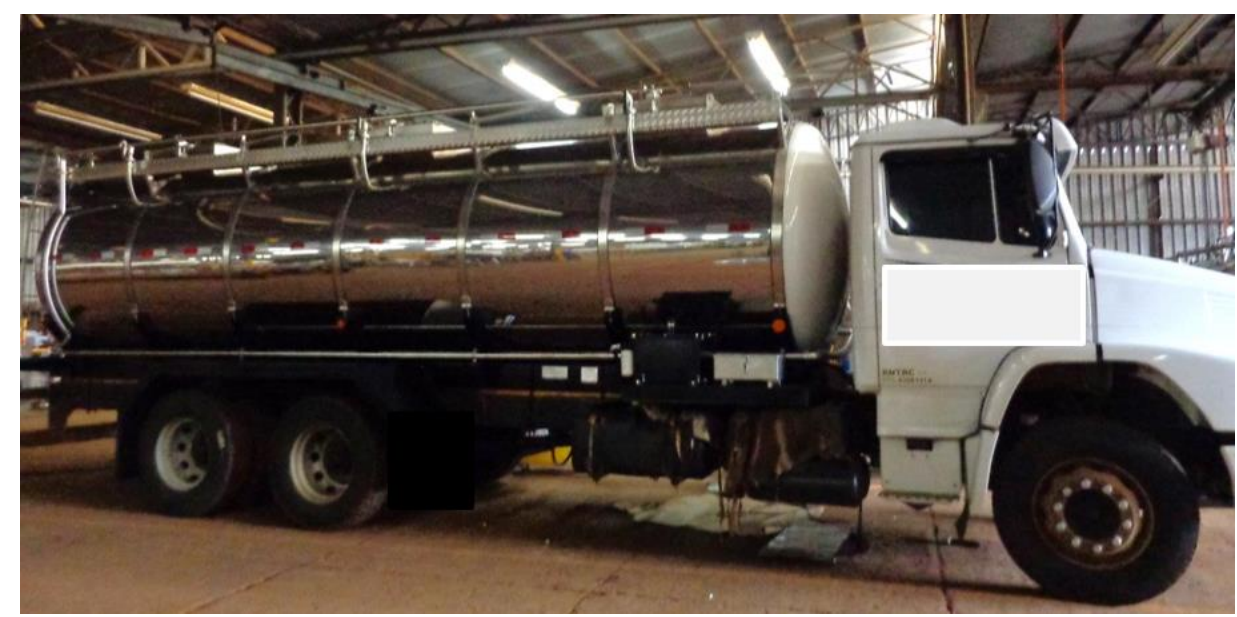

Fonte: Os autores.

O mapeamento do fluxo de valor buscou elaborar um mapa que ilustra como é o fluxo de materiais e informações, iniciando na cadeia de fornecedores e percorrendo os setores da indústria até o cliente. O objetivo do mapa do fluxo de valor é a partir da análise, entender o que está ou não agregando valor ao produto, identificando problemas e desperdícios, propondo melhorias. Desenvolveu-se o mapa do fluxo de valor atual e futuro.

\section{Resultados e discussão}

\section{Mapeamento do processo produtivo}

Na busca de conhecimento mais detalhado da indústria para a realização do mapeamento do processo produtivo, primeiramente foram explorados os setores com o fim de compreender o processo produtivo. O mapeamento, ocorreu através do acompanhamento detalhado da produção observando o desempenho dos equipamentos, do funcionamento de cada um dos setores e a partir de depoimentos dos colaboradores, possibilitando compreender e aprofundar o conhecimento dos processos da indústria estudada, cujas informações foram utilizadas no desenvolvimento dos mapas de fluxo de valor.

A partir do pedido do cliente junto ao setor administrativo, a indústria oferece os modelos, as variações do catálogo e a possibilidade de customização de acordo com os requisitos que o cliente deseja investir. No Quadro 1 é possível visualizar o mapeamento dos processos e equipamentos necessários para a confecção de um tanque rodoviário cilíndrico de 15000 l. 
Quadro 1 - Mapeamento do processo de fabricação

\begin{tabular}{|c|c|c|}
\hline Processo & Equipamentos & Descrição \\
\hline Recebimento & 2 empilhadeiras & $\begin{array}{l}\text { Parte da matéria-prima é distribuída aos setores de destino, onde se inicia } \\
\text { a transformação dos itens. O material de grande porte é alocado no } \\
\text { pavilhão da indústria, e os demais no almoxarifado. }\end{array}$ \\
\hline \multirow[t]{2}{*}{ Corte } & $\begin{array}{l}2 \text { máquinas de corte } \mathrm{CNC} \\
\text { plasma }\end{array}$ & Cortes personalizados em chapas de aço inox e aço carbono. \\
\hline & 1 guilhotina & Cortes lineares em aço inox de até $9 \mathrm{~mm}$ e aço carbono até $10 \mathrm{~mm}$. \\
\hline \multirow{2}{*}{$\begin{array}{l}\text { Dobra } \\
\text { Rebarbadeira }\end{array}$} & 1 dobradeira CN & Peças em aço inox e carbono. Dobras da base de sustentação do tanque. \\
\hline & 1 lixadeira orbital & Remoção de rebarbas (excesso de material). \\
\hline \multirow{6}{*}{ Usinagem } & $\begin{array}{l}3 \text { serras para corte de } \\
\text { tubos perfis }\end{array}$ & $\begin{array}{l}\text { Uma serra utilizada para cortes de aço carbono, uma para aço inox e uma } \\
\text { serra CN (para maiores quantidades) para ambos os materiais. }\end{array}$ \\
\hline & $\begin{array}{l}3 \text { tornos: dois } \\
\text { convencionais e um CNC }\end{array}$ & $\begin{array}{l}\text { Acabamento e confecção de peças (eixos e roscas, e demais peças } \\
\text { cilíndricas), transformando o material bruto em peças, utilizadas na } \\
\text { produção dos componentes e adicionadas ao tanque. }\end{array}$ \\
\hline & 1 centro de usinagem & Peças que necessitam alguma conformidade ou acabamento mais preciso. \\
\hline & 1 fresadora CNC & $\begin{array}{l}\text { Mesma finalidade do centro de usinagem, porém, para menor número de } \\
\text { peças. }\end{array}$ \\
\hline & $\begin{array}{l}2 \text { prensas: pequena e } \\
\text { grande }\end{array}$ & $\begin{array}{l}\text { Prensa pequena: conformar itens pequenos (arruelas) e perfuração de } \\
\text { chapas para as passarelas superiores. Prensa grande: conformar os tampos } \\
\text { que são utilizados nos tambores dos tanques isotérmicos. }\end{array}$ \\
\hline & 1 rebordadeira & Confere borda ao tampo circular traseiro. \\
\hline $\begin{array}{l}\text { Produção de } \\
\text { componentes em } \\
\text { inox } 1\end{array}$ & $\begin{array}{l}1 \text { solda TIG e } 1 \text { lixadeira } \\
\text { orbital }\end{array}$ & $\begin{array}{l}\text { Setor abastecido por itens provenientes do almoxarifado, corte e dobra, e } \\
\text { usinagem. Realizada a solda e polimento. }\end{array}$ \\
\hline \multirow{2}{*}{$\begin{array}{l}\text { Montagem de } \\
\text { bomba hidráulica }\end{array}$} & 1 solda MIG e 1 solda TIG & $\begin{array}{l}\text { O componente é finalizado para ser acoplado aos tanques e caminhões. } \\
\text { Função: succionar o líquido para dentro do tanque. }\end{array}$ \\
\hline & Teste de funcionamento & $\begin{array}{l}\text { A bomba é testada para garantir o funcionamento, assegurando que não } \\
\text { tenha vazamento. }\end{array}$ \\
\hline $\begin{array}{l}\text { Produção de Berço e } \\
\text { Plataforma }\end{array}$ & \multirow{3}{*}{$\begin{array}{l}\text { Utiliza equipamentos de } \\
\text { outros setores para a } \\
\text { produção e no posto de } \\
\text { montagem da } \\
\text { plataforma, solda MIG }\end{array}$} & $\begin{array}{l}\text { Produzida uma estrutura que une tanque e caminhão. O cliente pode optar } \\
\text { por prender o tanque apenas nos berços, ou então em pés, que serão } \\
\text { presos na plataforma e no caminhão. }\end{array}$ \\
\hline $\begin{array}{l}\text { Produção Proteção } \\
\text { Lateral }\end{array}$ & & $\begin{array}{l}\text { Prepara itens que são montados no caminhão quando o mesmo já está na } \\
\text { montagem final. }\end{array}$ \\
\hline $\begin{array}{l}\text { Produção dos Pés } \\
\text { para Tanques }\end{array}$ & & $\begin{array}{l}\text { Litragens superiores a } 15000 \text { I aconselha-se que o suporte utilizado seja o } \\
\text { de pés, em virtude do mesmo ser mais reforçado. Em tanques de } 15000 \text { I } \\
\text { ainda é frequentemente optado pela plataforma com berço, em virtude de } \\
\text { seu custo reduzido. }\end{array}$ \\
\hline $\begin{array}{l}\text { Produção de } \\
\text { componentes em } \\
\text { inox } 2\end{array}$ & $\begin{array}{l}\text { Utiliza equipamentos de } \\
\text { outros setores para a } \\
\text { produção e no posto de } \\
\text { montagem, solda TIG }\end{array}$ & $\begin{array}{l}\text { Dá-se forma aos componentes de maior volume como escadas, tubulações, } \\
\text { corrimões e passarelas. }\end{array}$ \\
\hline \multirow{3}{*}{$\begin{array}{l}\text { Acabamento de } \\
\text { Itens }\end{array}$} & 4 politrizes & $\begin{array}{l}\text { Remove manchas e imperfeições, uniformizando os locais de solda para } \\
\text { que não fique nenhum tipo de resíduo no material. O setor de acabamento } \\
\text { de itens deixa o produto adequado esteticamente, gerando a satisfação do } \\
\text { cliente. }\end{array}$ \\
\hline & Jato de Granalha & $\begin{array}{l}\text { Usado em peças de aço carbono para limpar e uniformizar o metal que } \\
\text { posteriormente irá receber a pintura. }\end{array}$ \\
\hline & Pintura & O item é personificado com a cor selecionada pelo cliente. \\
\hline $\begin{array}{l}\text { Posto } 1 \text { - Corte de } \\
\text { Bobinas }\end{array}$ & 1 plasma manual & $\begin{array}{l}\text { Corte de bobinas aço inox utilizadas na montagem interna dos tanques. } \\
\text { Dependendo da litragem dos tanques será o tamanho das chapas cortada } \\
\text { das bobinas. }\end{array}$ \\
\hline $\begin{array}{l}\text { Posto } 2 \text { - Montagem } \\
\text { Vertical }\end{array}$ & $\begin{array}{l}1 \text { plasma manual; } 1 \text { solda } \\
\text { MIG; } 1 \text { solda TIG. }\end{array}$ & $\begin{array}{l}\text { A montagem dos tanques inicia com a montagem dos compartimentos } \\
\text { (tambores internos). No caso do tanque de } 15000 \text { I mapeado, o tanque } \\
\text { será dividido em compartimentos de } 5000 \text { I, com tolerância de até } 100 \text { I } \\
\text { por tambor. Com a solda MIG são realizadas as soldas externas, com a TIG, } \\
\text { as soldas internas do tambor interno em virtude de ser mais adequada } \\
\text { para entrar em contato com produtos alimentícios. O tempo médio para } \\
\text { que o conjunto de três tambores esteja pronto é de } 13 \mathrm{~h} 12 \mathrm{~min} \text {. }\end{array}$ \\
\hline
\end{tabular}




\begin{tabular}{|c|c|c|}
\hline \multirow{2}{*}{$\begin{array}{l}\text { Posto } 3 \text { - União dos } \\
\text { Tambores }\end{array}$} & 1 solda MIG & $\begin{array}{l}\text { União dos tambores para que tornem-se um tanque unificado. Soldam-se } \\
\text { as esperas para as tubulações que serão colocadas no posto 6. A união dos } \\
\text { tambores leva em média 13h12min para estar concluída. }\end{array}$ \\
\hline & Teste de vazamento & $\begin{array}{l}\text { Teste nos compartimentos para verificar se a solda está funcional. Espalha- } \\
\text { se na solda uma mistura de detergente com água e através de um } \\
\text { equipamento é injetado ar comprimido no tanque. }\end{array}$ \\
\hline Posto 4 - Ferração & 1 solda MIG & $\begin{array}{l}\text { Adicionar as ferrações para reforçar o tanque e prepará-lo para receber o } \\
\text { poliuretano e o revestimento no posto } 5 \text {. Para juntar a ferração com o } \\
\text { tanque interno, utiliza-se a solda MIG e quando necessário a plasma } \\
\text { manual. Leva em média 8h48min. }\end{array}$ \\
\hline \multirow[b]{2}{*}{$\begin{array}{l}\text { Posto } 5 \text { - } \\
\text { Revestimento }\end{array}$} & 1 solda MIG & $\begin{array}{l}\text { Aqui, o tanque começa a ter o formato final. O revestimento é feito com } \\
\text { chapas retiradas das bobinas de aço inox } 430 \text {. O tanque é revestido } \\
\text { utilizando a solda MIG. }\end{array}$ \\
\hline & Injetora de Poliuretano & $\begin{array}{l}\text { Na união das soldas das chapas de revestimento, ao longo do tanque, são } \\
\text { feitos pequenos orifícios para a injeção de poliuretano que expande-se e se } \\
\text { transforma em um produto sólido, com aspecto similar ao de espuma. Tem } \\
\text { função isolante, sendo que no caso do transporte de produtos alimentícios } \\
\text { é extremamente importante para manter suas propriedades. Leva em } \\
\text { média 8h48min para concluir. }\end{array}$ \\
\hline $\begin{array}{l}\text { Posto 6- } \\
\text { Acabamento }\end{array}$ & $\begin{array}{l}1 \text { solda TIG; } 1 \text { plasma } \\
\text { manual. }\end{array}$ & Adicionado ao tanque os componentes finais (passarela e escada). \\
\hline Montagem Final & 1 solda MIG & $\begin{array}{l}\text { Após finalizado, o tanque aguarda até a retirada do cliente, sendo instalado } \\
\text { no caminhão. }\end{array}$ \\
\hline Higienização & 1 mangueira & $\begin{array}{l}\text { Realizada no momento em que antecede a entrega ao cliente, onde a } \\
\text { mesma é feita com água, detergente e desengraxante. }\end{array}$ \\
\hline
\end{tabular}

Fonte: Os autores.

O acompanhamento e mapeamento do processo produtivo possibilita notar alguns pormenores que muitas vezes passam despercebidos, mas são relevantes e devem ser identificados. Por exemplo os desperdícios de matéria-prima, tempo empregado de maneira inadequada, deficiência de organização, entre outras dificuldades que apenas são observadas a partir de um estudo dedicado. Salienta-se a importância de realizar entrevistas com os colaboradores envolvidos com os processos de produção, pois além dos mesmos possuírem a experiência do dia a dia, demonstrar que a participação dos colaboradores é fundamental para que o processo ocorra bem e o produto seja entregue com qualidade ao cliente e que os mesmos fazem parte das mudanças, os motiva na implementação das melhorias.

\section{Mapeamento do fluxo de valor}

O mapeamento de fluxo de valor, foi realizado com base no tanque isotérmico de $15000 \mathrm{I}$, utilizando os conhecimentos da indústria adquiridos através do mapeamento do processo.

Através do acompanhamento da produção do tanque isotérmico de 15000 I desde o seu início até o final foi desenvolvida uma representação visual do fluxo de material e de informação, identificando problemas e desperdícios onde posteriormente foi desenhado um mapa sugerindo o estado futuro.

É importante ressaltar que os mapas de fluxo de valor foram desenvolvidos a partir da visão macro da empresa e seus processos, com o intuito de iniciar organizando o todo e situações mais urgentes para assim, ir evoluindo aos pequenos detalhes. Será sugerida a inserção de novas rotinas e nova cultura, portanto faz parte do cuidado para que não exista estranhamento e rejeição por parte de colaboradores. 


\section{Mapeamento do fluxo de valor atual}

O mapeamento do fluxo de valor atual possibilitou enxergar a forma com que o processo produtivo se comporta, permitindo verificar oportunidades de melhorias como gargalos e atrasos nos processos produtivos. O mapeamento do fluxo de valor deu-se a partir do estudo e das observações realizadas no mapeamento do processo produtivo.

\section{Mapeamento do fluxo de valor futuro}

Após o mapeamento do fluxo de valor atual desenvolveu-se o mapeamento do fluxo de valor futuro com as sugestões de melhorias. Com o mapa de fluxo do valor atual é possível ter melhor entendimento do que não está agregando valor ao produto final ou dificultando que os processos ocorram da melhor forma. Observa-se na Figura 2 o mapeamento do fluxo de valor atual, e o futuro na Figura 3.

A identificação de melhorias oportuniza a aplicação adequada de ferramentas para redução de desperdícios e aumento de eficiência produtiva. Processos que não geram valor e que devem ser evitados ou eliminados.

O fluxo de informações é tão importante quanto o fluxo do processo, estes dois fluxos estão interligados e o mapeamento do fluxo de valor atinge a ambos.

Conforme identificado no mapeamento do fluxo de valor atual, problemas como, cartão de produção com informações insuficientes, falha na comunicação e estoque setorial sem controle poderiam ser amenizados com a programação e controle de produção adequada e bem definida. Como forma de atingir este objetivo, o apropriado seria a implementação de um PCP (Planejamento e Controle da Produção) responsável por definir capacidade produtiva, acionar e controlar a produção com o apoio de um sistema ERP (Enterprise Resource Planning), cuja finalidade do sistema é a integração dos dados para auxiliar nas atividades da indústria, tomadas de decisões, planejamento dos recursos e roteiros de produção possibilitando desta forma, realizar o controle efetivo do que acontece dentro da indústria.

Um fator importante a ser aplicado em toda a indústria, da parte administrativa ao chão de fábrica, a implantação do programa 5'S. Resultando em melhorias de qualidade, organização e otimização, sendo grande aliado na resolução das necessidades de organização e identificação para a empresa. Este programa é a implantação de uma nova cultura que necessitara o comprometimento de todos os colaboradores da indústria para gerar os resultados esperados.

Para a produção de peças que normalmente ficam armazenadas nos setores de trabalho ou até mesmo aguardando para a retirada, aconselha-se adotar a cultura do cartão de identificação de peças aprovadas e reprovadas, bem como identificações nas partes frontais das prateleiras, desde o almoxarifado até as prateleiras distribuídas pela indústria.

A comunicação interna é algo fundamental dentro de uma organização, notou-se com muita intensidade a falha na comunicação principalmente por em sua grande parte, a produção ser acionada 
verbalmente. Os operadores acabam tornando-se seus próprios líderes e verificam eles mesmos o que produzir e quando, no momento em que não tomam conhecimento do que está sendo produzido pela linha, o risco de faltar componentes é alto. Os próprios operadores direcionam-se ao almoxarifado e verificam se o estoque mínimo de peças ainda não está acionado ou quando um tanque começa a ser montado, eles buscam verificar qual tanque será produzido e os componentes que o mesmo vai necessitar, caso contrário irá parar a produção e consequentemente atrasar o andamento dos processos e a entrega pela falta de algum componente.

O controle do almoxarifado é algo fundamental dentro de uma organização, pois normalmente este detém a maior parte do inventário. Identificou-se a inexistência de um controle efetivo das entradas e saídas do inventário. Para tanto, idealizou-se um modelo de cartão de controle individual de estoque, cuja intenção é ter um para cada tipo de peça podendo estar localizado na parte interna de cada uma das caixas do almoxarifado e quando o almoxarife for retirar as peças já realize o controle de imediato, possibilitando assim, lançamentos efetivos no sistema ERP e controle de peças mínimas. Para que esta iniciativa realmente funcione, os únicos a ter acesso ao almoxarifado devem ser os almoxarifes, proibindo a entrada e interferência de terceiros sem o real conhecimento do funcionamento do almoxarifado.

Outro problema identificado constantemente é a falta de desenho do produto e instruções do funcionamento dos equipamentos adequadas, aumentando o risco de falhas que irão transformar-se em retrabalho e tornando a empresa refém do conhecimento do operador que trabalha naquela função diariamente. É interessante destacar, que os operadores sentem a necessidade de solucionar este problema, pois a falta do desenho do produto gera retrabalho para eles mesmo. 


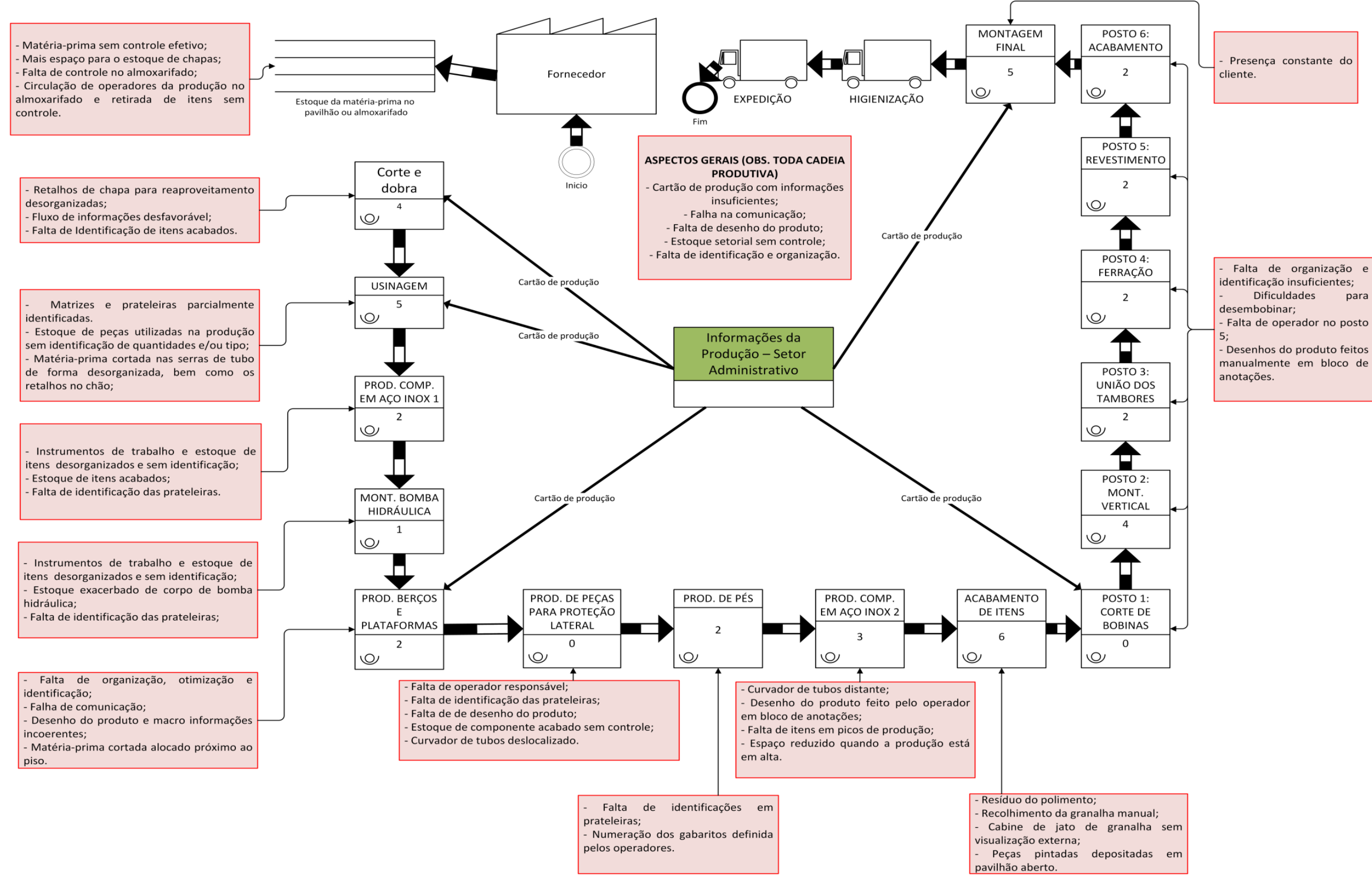

Figura 2 - Mapeamento do fluxo de valor atual. Fonte: Os autores. 


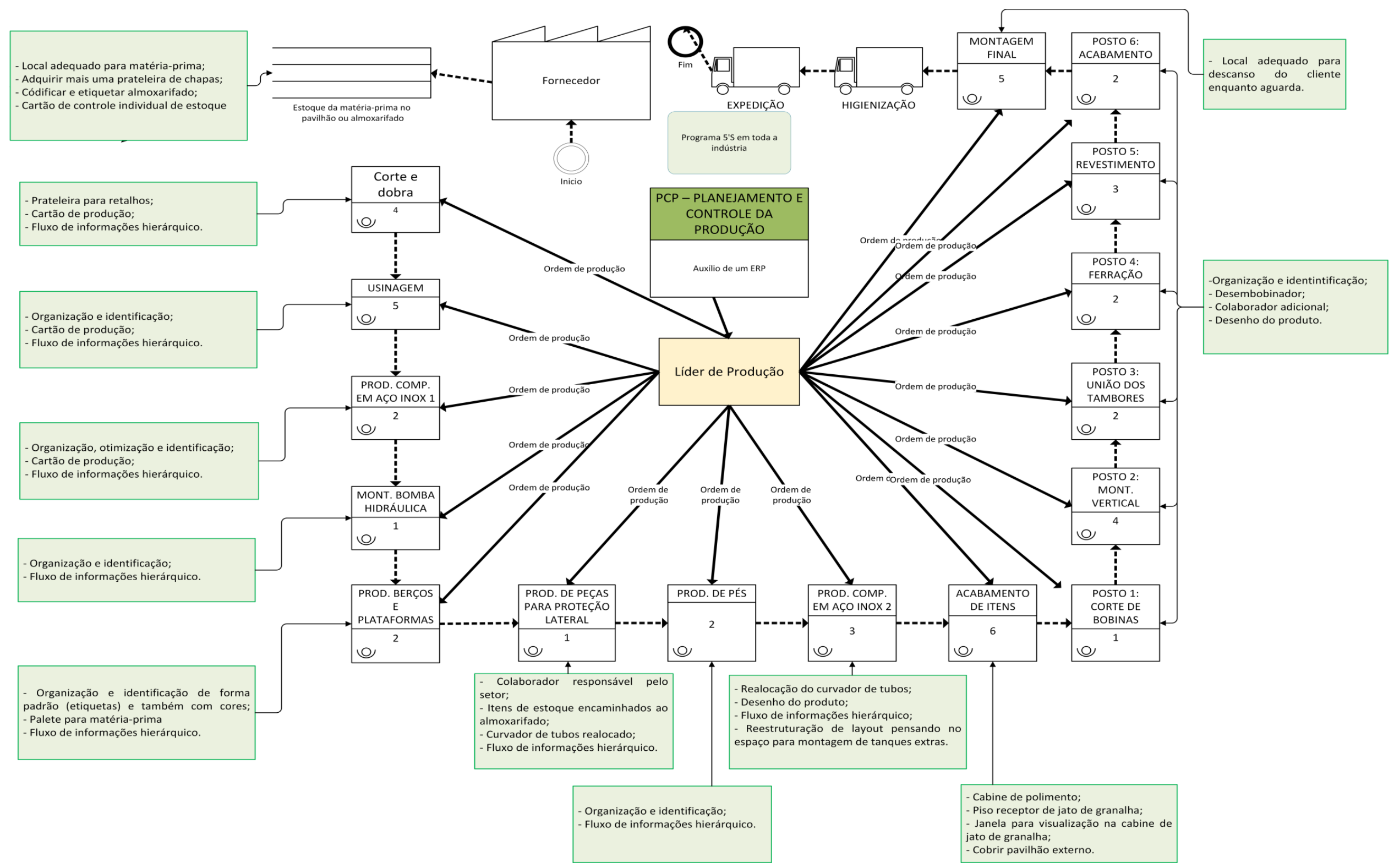

Figura 3 - Mapeamento do fluxo de valor futuro

Fonte: Os autores. 
Os operadores devem ter o desenho do produto com as dimensões do que está sendo produzido, oferecido pelo setor administrativo, pois se a responsabilidade ficar apenas com o operador, a empresa torna-se refém do conhecimento, experiência e especificações daquela pessoa. Isso acarretaria em uma série de erros no produto, perdas e atraso em entregas até que outra pessoa seja treinada e reaprenda o que fazer.

Elaborou-se uma tabela síntese (Quadro 2), com os pontos prioritários encontrados a partir do estudo que foi realizado.

\section{Quadro 2 - Síntese dos pontos prioritários}

\begin{tabular}{|c|c|c|c|}
\hline Atividade & Diagnóstico & Ação & Progressos da implementação de melhorias \\
\hline $\begin{array}{l}\text { Aspectos } \\
\text { gerais }\end{array}$ & $\begin{array}{l}\text { Cartão de produção } \\
\text { com informações } \\
\text { insuficientes }\end{array}$ & $\begin{array}{l}\text { Implementação de um } \\
\text { PCP (Planejamento e } \\
\text { Controle da Produção) } \\
\text { com o apoio de um } \\
\text { sistema ERP (Enterprise } \\
\text { Resource Planning) }\end{array}$ & $\begin{array}{l}\text { Ordem de produção completa. Controle de } \\
\text { produção eficiente. Roteiro de produção. } \\
\text { Definir a capacidade produtiva, acionar e } \\
\text { controlar a produção, cuja finalidade do } \\
\text { sistema é a integração dos dados para } \\
\text { auxiliar nas atividades da indústria, tomadas } \\
\text { de decisões e o planejamento dos recursos } \\
\text { de produção, possibilitando realizar o } \\
\text { controle efetivo do que acontece dentro da } \\
\text { indústria }\end{array}$ \\
\hline $\begin{array}{l}\text { Aspectos } \\
\text { gerais }\end{array}$ & $\begin{array}{l}\text { Comunicação } \\
\text { ineficiente e } \\
\text { informações } \\
\text { equivocadas } \\
\end{array}$ & $\begin{array}{l}\text { Fluxo de informações } \\
\text { hierárquico e } \\
\text { formalizado }\end{array}$ & $\begin{array}{l}\text { Informações coerentes e precisas, evitando } \\
\text { distorções, conflitos entre colaboradores e } \\
\text { erros de produção }\end{array}$ \\
\hline $\begin{array}{l}\text { Aspectos } \\
\text { gerais }\end{array}$ & $\begin{array}{l}\text { Carência de desenho } \\
\text { do produto e de } \\
\text { procedimentos } \\
\text { padronizados. } \\
\text { Desenho do produto } \\
\text { realizado pelo próprio } \\
\text { operador }\end{array}$ & $\begin{array}{l}\text { Implementar banco de } \\
\text { desenhos dos produtos } \\
\text { da indústria e } \\
\text { procedimento } \\
\text { operacional padrão } \\
\text { (POP) }\end{array}$ & $\begin{array}{l}\text { O intuito desta ação é garantir a } \\
\text { padronização da qualidade e que as tarefas } \\
\text { sejam executadas conforme o planejado. } \\
\text { Desta forma também, a indústria tem maior } \\
\text { domínio das informações dos produtos }\end{array}$ \\
\hline $\begin{array}{l}\text { Aspectos } \\
\text { gerais }\end{array}$ & $\begin{array}{l}\text { Estoque sem controle } \\
\text { e identificação }\end{array}$ & $\begin{array}{l}\text { Implementação do } \\
\text { programa 5's }\end{array}$ & $\begin{array}{l}\text { Melhorias de qualidade organizacional e de } \\
\text { saúde do trabalhador, organização e } \\
\text { otimização }\end{array}$ \\
\hline $\begin{array}{l}\text { Corte e } \\
\text { dobra }\end{array}$ & $\begin{array}{l}\text { Estoque de retalhos } \\
\text { de chapas }\end{array}$ & $\begin{array}{l}\text { Produzir um separador } \\
\text { de chapas }\end{array}$ & $\begin{array}{l}\text { Organização dos retalhos por espessuras } \\
\text { para facilitar a localização e reutilização da } \\
\text { matéria-prima, para assim, promover a } \\
\text { cultura do reaproveitamento resultando em } \\
\text { redução de custos }\end{array}$ \\
\hline $\begin{array}{l}\text { Cabine de } \\
\text { polimento }\end{array}$ & Resíduos de polimento & $\begin{array}{l}\text { Implementação de uma } \\
\text { cabine de polimento } \\
\text { com exaustão }\end{array}$ & $\begin{array}{l}\text { Bem-estar e segurança do funcionário aliado } \\
\text { à melhoria de performance para executar a } \\
\text { atividade }\end{array}$ \\
\hline $\begin{array}{l}\text { Cabine de } \\
\text { jato de } \\
\text { granalha }\end{array}$ & $\begin{array}{l}\text { Recolhimento de } \\
\text { granalha manual }\end{array}$ & $\begin{array}{l}\text { Recolhimento } \\
\text { automático da granalha }\end{array}$ & $\begin{array}{l}\text { Redução do tempo em que o colaborador } \\
\text { necessita dedicar para recolher a granalha. }\end{array}$ \\
\hline $\begin{array}{l}\text { Secagem da } \\
\text { pintura }\end{array}$ & $\begin{array}{l}\text { Peças pintadas } \\
\text { depositadas em } \\
\text { pavilhão externo }\end{array}$ & Cobrir pavilhão externo & $\begin{array}{l}\text { Peças finalizadas protegidas, evitando } \\
\text { retrabalhos e custos. }\end{array}$ \\
\hline $\begin{array}{l}\text { Postos de } \\
\text { montagem }\end{array}$ & $\begin{array}{l}\text { Dificuldades no corte } \\
\text { de chapas das bobinas }\end{array}$ & $\begin{array}{l}\text { Adquirir um } \\
\text { desembobinador }\end{array}$ & $\begin{array}{l}\text { Melhorias na qualidade de vida do } \\
\text { trabalhador, pois irá realizar menos esforço } \\
\text { físico ao manusear as bobinas de matéria- } \\
\text { prima redução de tempo com o corte das } \\
\text { chapas. }\end{array}$ \\
\hline
\end{tabular}

Fonte: Os autores. 
Com estas ferramentas de auxilio no controle de produção juntamente com o PCP, o fluxo de informações torna-se mais coerente, e os operadores respondem sempre àquilo que thes for passado de maneira formalizada. Isso evita atritos entre operadores e erros que acontecem da atual forma com que o fluxo de informações é repassado. Aconselha-se que o fluxo da informação aconteça respeitando a ordem hierárquica, assim o colaborador conduz seu trabalho a partir das orientações de seu líder.

Através dos dados retirados da análise dos processos, referente à busca por retalhos e no recolhimento manual da granalha na cabine, realizou-se um cálculo para comprovar que pequenas ações resultam em desperdícios de tempo e consequentemente de valores que poderia estar sendo investido em algo, conforme é possível verificar no Quadro 3.

O Quadro 3 refere-se a seguinte situação: estima-se que a busca por retalhos aconteça pelo menos uma vez por turno de trabalho e em cada busca o operador gasta aproximadamente 8 min, o ano de 2017 contou com aproximadamente 251 dias úteis, totalizando 502 buscas no ano. Com 502 buscas em um ano, obtém-se o número de 66,93 h desperdiçadas. Conforme informado pela empresa o piso salarial do operador é de $\mathrm{R} \$ 5,50$, resultando em $\mathrm{R} \$ 368,13$ ao ano, gastos com a busca por retalhos.

Com o recolhimento manual da granalha, estimou-se que a mesma seja recolhida duas vezes por semana e para que isso aconteça, são gastos $90 \mathrm{~min}$. O ano de 2016 teve 52 semanas, resultando em 104 recolhimentos manuais de granalha. O total de tempo gasto com os 104 recolhimentos é de $156 \mathrm{~h}$ no ano, com o piso salarial de $\mathrm{R} \$ 5,50$ tem-se ao final do ano $\mathrm{R} \$ \mathrm{858}, 00$ desperdiçados.

Quadro 3 - Busca por retalhos e recolhimento da granalha

\begin{tabular}{|c|c|c|c|c|c|c|c|c|}
\hline Situação & $\begin{array}{c}\text { Frequê } \\
\text { ncia }\end{array}$ & $\begin{array}{c}\text { Tempo } \\
\text { gasto em } \\
\text { min }\end{array}$ & $\begin{array}{c}\text { No } \\
\text { ano }\end{array}$ & $\begin{array}{c}\text { Frequência } \\
\text { total no ano }\end{array}$ & $\begin{array}{c}\text { Tempo } \\
\text { desperdi } \\
\text { çado em } \\
\text { min }\end{array}$ & $\begin{array}{c}\text { Tempo } \\
\text { desperdiça } \\
\text { do em } h\end{array}$ & $\begin{array}{c}\text { Piso } \\
\text { salarial/h } \\
\text { R\$ }\end{array}$ & $\begin{array}{c}\text { Valor } \\
\text { Total } \\
\text { desperdi- } \\
\text { çado }\end{array}$ \\
\hline $\begin{array}{c}\text { Busca por retalhos } \\
\text { que possam ser } \\
\text { reaproveitados }\end{array}$ & $\begin{array}{c}2 \text { vezes } \\
\text { por dia }\end{array}$ & 8 & $\begin{array}{c}251 \\
\text { dias } \\
\text { úteis }\end{array}$ & 502 & 4016 & 66,933 & $R \$ 5,50$ & $R \$ 368,13$ \\
\hline $\begin{array}{c}\text { Recolhimento } \\
\text { manual da } \\
\text { granalha }\end{array}$ & $\begin{array}{c}2 \text { vezes } \\
\text { por } \\
\text { semana }\end{array}$ & 90 & $\begin{array}{c}52 \\
\text { seman } \\
\text { as }\end{array}$ & 104 & 9360 & 156 & $R \$ 5,50$ & $R \$ 858,00$ \\
\hline
\end{tabular}

Fonte: Os autores.

Atualmente as peças após passarem pelo processo de pintura ficam depositadas em um pavilhão externo e consequentemente sujeitas as intempéries, para tanto, recomenda-se que o pavilhão externo seja coberto, possibilitando um local adequado para o deposito das peças prontas evitando retrabalhos e possibilitando desta forma, que o pavilhão seja melhor utilizado. 
O estudo encontrou desafios em virtude de carências crônicas naturalizadas no dia a dia da organização, sendo assim, a necessidade primordial foi de visualizar o todo da indústria, investigar os processos de maneira macro.

Desta forma, após implementadas as ações propostas no presente estudo, sugere-se para trabalhos futuros que se realize mapeamentos específicos em cada um dos setores e processos, buscando identificar novas oportunidades de melhorias a serem realizadas, visto que a melhoria deve ser contínua, para que cada vez mais a organização otimize e melhore seus processos produtivos, qualidade e consequentemente lucros.

\section{Conclusões}

O presente estudo foi realizado com o propósito de responder o seguinte problema da pesquisa: Qual a melhor maneira de identificar e propor melhorias no processo produtivo de tanques isotérmicos rodoviários, a fim de contribuir com a empresa e na qualidade do produto final? Cuja resposta do problema deu-se através das sugestões de melhorias identificadas a partir dos mapeamentos realizados.

Acompanhou-se o processo de produção de tanques isotérmicos rodoviários cilíndricos de 15000 I com o objetivo de propor ações de melhorias. O mapeamento do processo produtivo realizado possibilitou ampliar o conhecimento referente à indústria.

O mapa do fluxo de valor desenvolvido teve como propósito, observar mais detalhadamente o fluxo de materiais e informações da cadeia produtiva do tanque isotérmico objetivado. O mapeamento do fluxo de valor atual teve como objetivo visualizar a forma com que o processo produtivo se comporta e desta forma, tornar possível verificar problemas e oportunidades de melhorias no decorrer da produção.

Já o mapeamento do fluxo de valor futuro, apresenta a proposição das melhorias a serem realizadas através de diagnósticos feitos a partir dos dados levantados com o mapeamento do processo e do fluxo de valor atual.

O presente estudo é de extrema relevância para a empresa laboratório, pois com a implementação das melhorias propostas, é possível também revelar problemas que possam estar ocorrendo de forma imperceptível. Pois quando se inicia um trabalho de melhoria contínua, organização e controle tornam-se aparentes, mostrando muitas vezes problemas que possam estar mascarados.

Como forma de manter-se competitivo no mercado, as organizações precisam buscar constantemente melhorias, seja inovando ou melhorando seus processos, com o objetivo de, que os produtos oferecidos sejam fabricados da forma mais adequada, garantindo a qualidade ao consumidor, de forma ágil e organizada com o menor custo de produção. 


\section{Referências}

Alhuraish, I., Robledo, C., \& Kobi, A. (2017). A comparative exploration of lean manufacturing and six sigma in terms of their critical success factors. Journal of Cleaner Production, 164, 325-337. https://doi.org/10.1016/j.jclepro.2017.06.146

Atieh, A. M., Kaylani, H., Almuhtady, A. \& Tamini, O. A. (2016). A value stream mapping and simulation hybrid approach: application to glass industry. The International Journal of Advanced Manufacturing Technology, 84(5-8), 1573-1586. https://doi.org/10.1007/s00170-015-7805-8

Bartz, A. P. B., Weise, A. D. \& Ruppenthal, J. E. (2013). Aplicação da manufatura enxuta em uma indústria de equipamentos agrícolas. Ingeniare. Revista chilena de ingeniería, 21(1) 147-158. https://doi.org/10.4067/S0718-33052013000100013

Chahal, V. \& Narwal, M. S. (2017). An empirical review of lean manufacturing and their strategies. Management Science Letters, 7(7), 321-336. https://doi.org/10.5267/j.msl.2017.4.004

Condé, G. C., \& Martens, M. L. Projetos lean manufacturing para geração de portfólio: uma revisão da literatura. Exacta - EP, São Paulo, v. 16, n. 1, p. 103-122, 2018.

https://doi.org/10.5585/exactaep.v16n1.7128

Helleno, AL. L., Moraes, A. J. I., \& Simon, A. T. (2017). Integrating sustainability indicators and Lean Manufacturing to assess manufacturing processes: Application case studies in Brazilian industry. Journal of Cleaner Production, 153, 405-416. https://doi.org/10.1016/j.jclepro.2016.12.072

Koenigsaecker, G. (2011). Liderando a Transformação Lean nas Empresas (1a ed.). Porto Alegre: Bookman.

Leite, J. V. G. A., Cotrim, S. L., Leal, G. C. L., \& Galdamez, E. V. C. (2017). Melhoria de Processo Operacional Utilizando Mapa de Fluxo de Valor em Uma Indústria Metal Mecânica. Revista FSA, 14( 5), 146-170.

Nallusamy, S. (2016). Efficiency Enhancement in CNC Industry using Value Stream Mapping, Work Standardization and Line Balancing. International Journal of Performability Engineering, 12(5), 413 422.

Oliveira, R. B. M., Corrêa, R. A. \& Nunes, L. E. N. P. (2013). Uso da simulação computacional com o mapeamento do fluxo de valor para auxiliar na tomada de decisão. Exacta, 11(1), 47-57.

Prates, C. C. \& Bandeira, D. L. (2011). Aumento de eficiência por meio do mapeamento do fluxo de produção e aplicação do Índice de Rendimento Operacional Global no processo produtivo de uma empresa de componentes eletrônicos. Gestão \& Produção, 18(4), 705-718.

https://doi.org/10.1590/S0104-530X2011000400003

Rother, M., \& Shook, J. (2012). Aprendendo a Enxergar: Mapeando o Fluxo de Valor para Agregar Valor e Eliminar o Desperdício. São Paulo: Lean Institute Brasil.

Santos, L. A., Hammes, J., Luz, A. C. G., Godoy, L. P., \& Ardenghi, T. (2016). Layout celular: proposta e implantação em empresa start-up de tecnologia. Revista GEINTEC, 6(4), 3447-3460. https://doi.org/10.7198/geintec.v6i4.494

Tortorella, G. L., Vergara, L. G. L., \& Ferreira, E. P. (2017). Lean manufacturing implementation: an assessment method with regards to socio-technical and ergonomics practices adoption. The International Journal of Advanced Manufacturing Technology, 89(9-12), 3407-3418. 
Womack, J. P. \& Jones, D. T. (2011). Enxergando o Todo: mapeando o fluxo de valor estendido. São Paulo: Lean Institute Brasil.

Zahraee, S. M. (2016), A survey on lean manufacturing implementation in a selected manufacturing industry in Iran, International Journal of Lean Six Sigma, Vol. 7 No. 2, pp. 136-148. https://doi.org/10.1108/IJLSS-03-2015-0010. 